\title{
Recursos alimentares utilizados pelos peixes e estrutura trófica de quatro trechos no reservatório Capivara (Rio Paranapanema)
}

\author{
Sirlei Terezinha Bennemann ${ }^{1,3}$, Wanner Galves ${ }^{2}$ \& Luiz Gustavo Capra ${ }^{2}$ \\ ${ }^{1}$ Departamento de Biologia Animal e Vegetal/CCB, Universidade Estadual de Londrina - UEL, \\ Campus Universitário, CP 6001, CEP 86051-990, Londrina, PR, Brasil \\ ${ }^{2}$ Pós-graduação em Ciências Biológicas, Universidade Estadual de Londrina - UEL \\ ${ }^{3}$ Autor para correspondência: Sirlei Terezinha Bennemann, e-mail: sirlei@uel.br
}

BENNEMANN, S.T., GALVES, W. \& CAPRA, L.G. Food resources used by fishes and trophic structure of four stretches in Capivara reservoir (Paranapanema River). Biota Neotrop. 11(1): http://www.biotaneotropica. org.br/v11n1/en/abstract?article+bn01411012011.

\begin{abstract}
The diet of the main fish species was evaluated from three stretches located in the Capivara reservoir, Paranapanema River and from one stretch on Tibagi River, the latter under the reservoir influence. The diet of these species, by the percentage composition, with the food items grouped was distinct: detritus and aquatic insects in three stretches (Cinzas, Cruzália and Porecatu); crustaceans and aquatic insects in Tibagi stretch. The fish species were grouped in six trophic groups, according to the main food items consumed determined by the Alimentary Index (IAi): carcinophagous, detritivore, herbivore, insectivore, omnivore and piscivore. All the six trophic categories have been identified among the fishes from the Tibagi stretch, five in Cinzas stretch, whereas four categories among fishes from Cruzália and Porecatu. The generalist/oportunist species Astyanax altiparanae, Moenkhausia intermedia and Pimelodus maculatus were included in diferent trophic categories according to the stretch. Plagioscion squamosissimus, piscivore in Porecatu and Cruzália, shifted to carcinophagy in the Tibagi and Cinzas stretches. The trophic structure and the abundance of the main fish species were different in each stretch, with the predominance of three species in each one, and always one of the introduced species figured among the three.
\end{abstract}

Keywords: Paranapanema River basin, feeding fish, reservoirs, resources origin.

BENNEMANN, S.T., GALVES, W. \& CAPRA, L.G. Recursos alimentares utilizados pelos peixes e estrutura trófica de quatro trechos no reservatório Capivara (Rio Paranapanema). Biota Neotrop. 11(1): http://www. biotaneotropica.org.br/v11n1/pt/abstract?article+bn01411012011.

Resumo: Foi avaliada a dieta das principais espécies de peixes e a estrutura trófica de três trechos no reservatório de Capivara, no Rio Paranapanema, localizados em Porecatu, Cruzália e Cinzas e de um trecho que sofre sua influência, no Rio Tibagi. A dieta destas espécies, pela composição percentual, com os itens alimentares agrupados foi: detritos e insetos aquáticos em três trechos (Cinzas, Cruzália e Porecatu) e crustáceos e insetos aquáticos no trecho Tibagi. Pelo Índice Alimentar (IAi) determinou-se os alimentos principais para cada espécie, e de acordo com eles, as espécies foram classificadas em seis categorias tróficas: carcinófaga, detritívora, herbívora, insetívora, onívora e piscívora. No trecho Tibagi foram verificadas seis categorias; no trecho Cinzas cinco e em Cruzália e Porecatu, quatro. As espécies generalistas/oportunistas: Astyanax altiparanae, Moenkhausia intermedia e Pimelodus maculatus mudaram de categoria trófica conforme o trecho. Plagioscion squamosissimus, piscívora em Porecatu e Cruzália, mudou para carcinófaga nos trechos Tibagi e Cinzas. A estrutura trófica, assim como a composição das principais espécies em abundância de exemplares, foi distinta em cada trecho, onde ocorreu o predomínio de três espécies, tendo sempre entre elas uma das espécies introduzidas.

Palavras-chave: bacia do Rio Paranapanema, alimentação de peixes, reservatórios, origem recursos. 


\section{Introdução}

Em várias, dentre as bacias hidrográficas brasileiras, já existem grandes reservatórios para fins hidrelétricos, que atualmente devem estar em torno de 600, conforme Agostinho et al. (2007). Estes reservatórios possuem características distintas, tanto pela idade como pelo tamanho e, pelas características da bacia de drenagem ou região. Considerando essa heterogeneidade dos reservatórios, é esperado que existam variações na diversidade ictiofaunística, bem como na disponibilidade de recursos alimentares para os peixes nestes ambientes.

Os estudos sobre a estrutura trófica e recursos alimentares utilizados pelos peixes em reservatórios são restritas a algumas bacias e regiões. A bacia do Rio Paraná, com maior número de hidrelétricas no Brasil (Kelman et al. 2002) é também a bacia hidrográfica que possui o maior número de pesquisas, sendo a maior parte destes reservatórios de grande porte. Em reservatórios no Estado do Paraná os peixes do reservatório de Segredo, na bacia do Rio Iguaçu, tiveram suas dietas estudadas por Hahn et al. (1997); no reservatório Itaipu, na bacia do Rio Paraná, a estrutura trófica foi analisada por Hahn et al. (1998); 24 reservatórios do Estado do Paraná e bacias limítrofes foram avaliados em sua estrutura trófica por Fugi et al. (2005) e o reservatório Capivari por Abelha et al. (2005).

No Rio Paranapanema, na área de divisa dos Estados do Paraná e São Paulo, atualmente existe dez usinas hidrelétricas instaladas (Duke Energy International 2003). Alguns destes reservatórios foram estudados, e, entre estes, o reservatório Jurumirim foi investigado em aspectos ecológicos da ictiofauna e produção pesqueira (Carvalho \& Silva 1999) e sobre a composição ictiofaunística por Castro et al. (2003); no reservatório de Rosana, Casatti et al. (2003) investigaram a dieta de peixes de pequeno porte, e no reservatório de Salto Grande, Dias \& Garavello (1998) estudaram a ecologia das comunidades de peixes.

Na região média do Rio Paranapanema está localizado o reservatório Capivara que é de grande porte e um dos mais antigos, formado em 1975. Este reservatório e áreas de sua influência vêm sendo investigados na última década e constam nos estudos realizados por Hoffmann et al. (2005) que inventariaram a ictiofauna em quatro trechos; Bennemann et al. (2006) analisaram dinâmica trófica de Plagioscion squamosissimus (Heckel, 1840) e Teixeira \& Bennemann (2007) descreveram a dieta e ecomorfologia das principais espécies de peixes de um trecho. $\mathrm{O}$ trecho mais investigado sob os aspectos de ecologia trófica foi uma área de influência do reservatório Capivara, localizada no Rio Tibagi (Bennemann et al. 2000, Lobón-Cerviá \& Bennemann 2000, Bennemann \& Shibatta 2002).

Em vários reservatórios analisados por Hahn \& Fugi (2007) foram verificadas mudanças quanto à disponibilidade de alimentos para os peixes, que diminuem ao longo do tempo. Entretanto, no Brasil, ainda são raras as publicações sobre a estrutura trófica em reservatórios de grande porte e antigos. O reservatório Capivara, considerado um reservatório antigo, ainda não teve analisada a composição da dieta das espécies de peixes e sua estrutura trófica ainda não é conhecida. Este estudo teve o objetivo de conhecer quais os principais recursos alimentares consumidos pelas espécies de peixes dominantes, e verificar a estrutura trófica em quatros trechos do reservatório Capivara, no Rio Paranapanema.

\section{Material e Métodos}

\section{1. Área de estudo}

Os trechos amostrados estão localizados no Rio Paranapanema (municípios de Porecatu, Cruzália e na foz do Rio Cinzas) e em um trecho que sofre sua influência, localizado no Rio Tibagi, no município de Sertanópolis (PR). Esses trechos, a seguir denominados de Porecatu, Cruzália, Cinzas e Tibagi, respectivamente, apresentam características distintas, principalmente quanto à profundidade e à extensão das áreas que contêm vegetação aquática. De cada trecho, localizado geograficamente através do aparelho de GPS, foi realizada a tomada de dados de transparência da água através de disco de Secchi, e da profundidade através de um profundímetro.

O trecho Porecatu localiza-se próximo à foz do Rio Vermelho, e fica no reservatório propriamente dito, distante $300 \mathrm{~m}$ da Usina

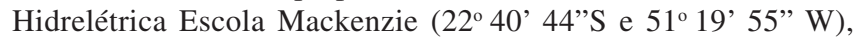
caracterizando-se, em sua maior extensão, por altas profundidades (15 a $70 \mathrm{~m})$. Nesse trecho o fundo é rochoso, existem afloramentos em diversas baías, as águas são semi-lóticas e de alta transparência (até $6 \mathrm{~m}$ ) e a vegetação ciliar é escassa. Macrófitas aquáticas estão presentes nas áreas marginais, de menor profundidade.

O trecho Cruzália ( $22^{\circ} 46^{\prime} 14^{\prime \prime} \mathrm{S}$ e $\left.50^{\circ} 50^{\prime} 34^{\prime \prime} \mathrm{W}\right)$ é formado pelas baías do reservatório, e suas águas são lênticas. Os locais mais próximos do canal do rio têm profundidade média de $6 \mathrm{~m}$ e transparência de aproximadamente $1 \mathrm{~m}$. A vegetação ciliar nativa é ausente, existindo pastos alagáveis e macrófitas aquáticas.

O trecho Tibagi (2301' $16^{\circ}$ ' S e 50 57' 13” W) localiza-se na porção do Rio Tibagi (principal afluente do Rio Paranapanema) e sofre influência do reservatório, mantendo as características de rio. Trata-se de um ambiente de transição entre os ecótonos de rio e de reservatório. Nesse trecho o Rio Tibagi atinge $25 \mathrm{~m}$ de profundidade no leito, e, próximo das margens e baías, cerca de $1 \mathrm{~m}$, onde a vegetação aquática é abundante e a vegetação ciliar é escassa. As águas são semi-lóticas, com transparência variável $(0,7$ a $0,95 \mathrm{~m})$. O leito é formado por rochas basálticas, que afloram na superfície da água em vários pontos, e o fundo apresenta grandes porções de lodo e argila.

O trecho Cinzas (22 $56^{\circ} 16^{\prime \prime} \mathrm{S}$ e $50^{\circ} 31^{\prime} 37^{\prime \prime} \mathrm{W}$ ) localiza-se na foz do Rio Cinzas, na porção lótica do rio. O trecho analisado teve profundidade variando entre 0,8 e $5,2 \mathrm{~m}$, com transparência entre 0,55 e 2,23 m. O fundo é composto por rochas, e em determinadas porções estas rochas se alternam com areia, contendo abrigos como pequenas cavernas, troncos e raízes submersas. Possui lagoas marginais com macrófitas em abundância, e escassos fragmentos de mata ao longo das margens, pois nestas áreas predominam as atividades de agricultura e pecuária. Na Figura 1 estão apontados os trechos amostrados e a localização dos mesmos.

$$
\begin{array}{r}
51^{\circ} 30^{\prime} \\
22^{\circ} 30^{\prime}+
\end{array}
$$

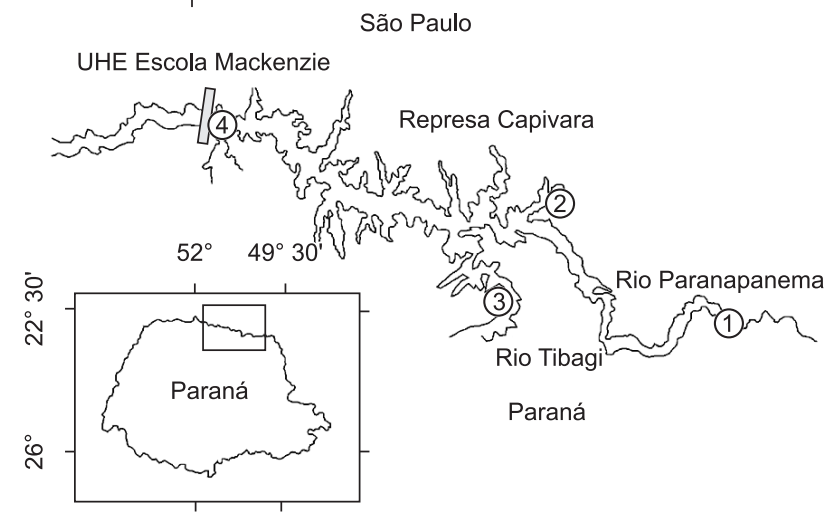

Figura 1. Trechos de amostragens dos peixes no reservatório Capivara, na porção média do Rio Paranapanema. 1) Cinzas; 2) Cruzália; 3) Tibagi; e 4) Porecatu.

Figure 1. Fish samples stretches in the Capivara reservoir, located in the middle portion of Paranapanema River. 1) Cinzas; 2) Cruzália; 3) Tibagi; and 4) Porecatu. 


\section{Metodologia}

Os exemplares das espécies utilizados neste estudo foram capturados no âmbito do projeto "Caracterização Biológica da Ictiofauna do Reservatório de Capivara - UHE Escola Mackenzie”, com resultados sobre a ictiofauna que estão publicados em Hoffmann et al. (2005). Em quatro trechos foram feitas coletas sazonais no período de um ano, entre maio de 2001 e abril de 2002, perfazendo 16 amostragens. Para a captura dos peixes foram utilizadas redes de espera de malhas com 1 a $10 \mathrm{~cm}$ entre nós opostos, totalizando $1.527 \mathrm{~m}^{2}$ de área. As redes foram expostas por um período de 24 horas, em cada amostragem. Os exemplares capturados foram fixados em formol 10\%, sendo depositados no Museu de Zoologia da Universidade Estadual de Londrina (MZUEL), como material testemunho.

Para as análises referentes à alimentação, foram utilizados exemplares de todas as espécies de peixes com conteúdo estomacal. Os tratos digestórios dos exemplares foram retirados e os seus conteúdos estomacais identificados com o auxílio de microscópio estereoscópico e manuais de identificação de animais aquáticos e terrestres.

Os itens alimentares identificados foram analisados pelos métodos de Composição Percentual ( $\mathrm{cp}$ ) e peso ( $\mathrm{g}$ ) úmido pelo método gravimétrico de Hyslop (1980). A composição percentual é definida como uma porcentagem da ocorrência de cada item alimentar em relação ao total geral de ocorrências, calculada pela Equação 1:

$$
\mathrm{Cp}=(\Sigma \mathrm{Ni} / \Sigma \mathrm{Nt}) \times 100
$$

onde: $\mathrm{Cp}=$ composição percentual, $\mathrm{Ni}=$ número de ocorrências do item $\mathrm{i}, \mathrm{Nt}=$ número total de ocorrências de todos os itens.

Na comparação dos recursos alimentares consumidos por todas as espécies de peixes, entre os quatro trechos do reservatório Capivara, os itens alimentares identificados foram agrupados em grandes categorias. Os percentuais totais destas categorias foram comparados, em peso e composição percentual.

As sete categorias em que os itens alimentares foram agrupados foram: peixes (diversas espécies de peixes e partes não identificadas, escamas e nadadeiras), insetos (pertencentes à formas aquáticas imaturas de insetos (Chironomidae, Ephemeroptera, Odonata, Ceratopogonidae, Caoboridae) e insetos adultos terrestres (Coleoptera, Hymenoptera); crustáceos (Copepoda, Cladocera, Ostracoda e a espécie - Macrobrachium amazonicum, uma espécie introduzida na bacia); vegetais (sementes de Polygonum sp. e gramíneas, incluindo também "quirela" (milho triturado utilizado como ceva por pescadores), sementes de trigo e outras culturas (restos de folhas de vegetais superiores e algas filamentosas), moluscos, detrito/sedimento e outros (diversos táxons animais).

Para visualizar a relação entre a composição da dieta das espécies de peixes e os trechos de amostragem foi utilizada a composição percentual dos itens alimentares em categorias, pela Análise de Componentes Principais (ACP) realizada no programa PAST (Hammer et al. 2004).

Foi também determinada a estrutura trófica com as espécies de peixes selecionadas pelo critério de ocorrência em todos os trechos ou, as espécies capturadas em maior abundância em número de exemplares em cada trecho. Para a comparação das espécies classificadas em categorias tróficas, os itens alimentares utilizados pelos peixes foram agrupados em grandes categorias, e calculados pelo Índice Alimentar (IAi) proposto por Kawakami \& Vazzoler (1980). Os cálculos para determinar os alimentos principais foram realizados utilizando o peso, em vez do volume dos itens. Cada espécie foi classificada dentro de determinada categoria trófica quando seu alimento preferencial perfez mais de 50\% nas categorias de alimento que consumiu, considerando-se os valores do IAi. Foram incluídas na categoria onívora as espécies que consumiram alimentos de origem vegetal e de origem animal em valores equivalentes.
Após a classificação das espécies em categorias tróficas a estrutura entre os trechos foi comparada utilizando os percentuais de exemplares capturados, por trecho.

\section{Resultados}

Nos quatro trechos foram analisadas 49 espécies e 2069 exemplares. No trecho Cinzas (41 espécies e 475 exemplares), Tibagi (33 espécies e 574 exemplares), Cruzália (22 espécies e 541 exemplares) e Porecatu (22 espécies e 479 exemplares), conforme Tabela 1.

Os alimentos utilizados, no total foram identificados em 41 itens consumidos pelas 49 espécies de peixes analisados. No trecho Tibagi, que teve maior número de indivíduos analisados, as espécies selecionadas utilizaram maior número de itens alimentares e também em maior peso (Tabela 2).

Os itens alimentares agrupados em sete amplas categorias quando comparados por trechos, pela composição percentual, indicaram que Detritos e Insetos foram as categorias de maiores valores nos três trechos (Cinzas, Cruzália e Porecatu), diferindo do trecho Tibagi, onde Crustáceos e Insetos foram os itens de maior ocorrência (Figura 2). Em valores percentuais por peso, a categoria Peixes foi a de maior importância em todos os trechos, seguidos de uma ordem distinta de categorias para cada um dos trechos (Figura 3).

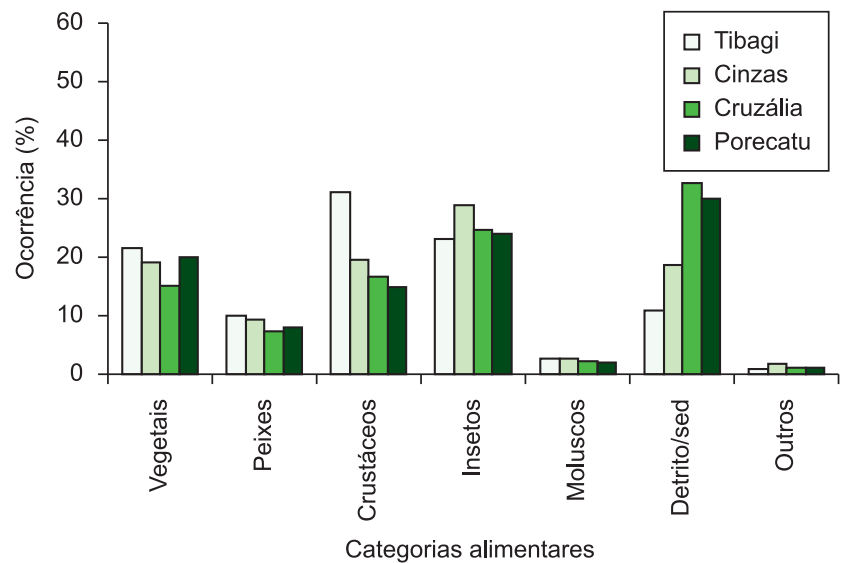

Figura 2. Composição percentual das categorias alimentares consumidas pelos peixes, no total, nos quatro trechos do reservatório Capivara, no período maio/2001 a abril/2002.

Figure 2. Percentage composition of food categories consumed by fish, in total, in the Capivara reservoir stretches, in the period of May 2001 to April 2002.

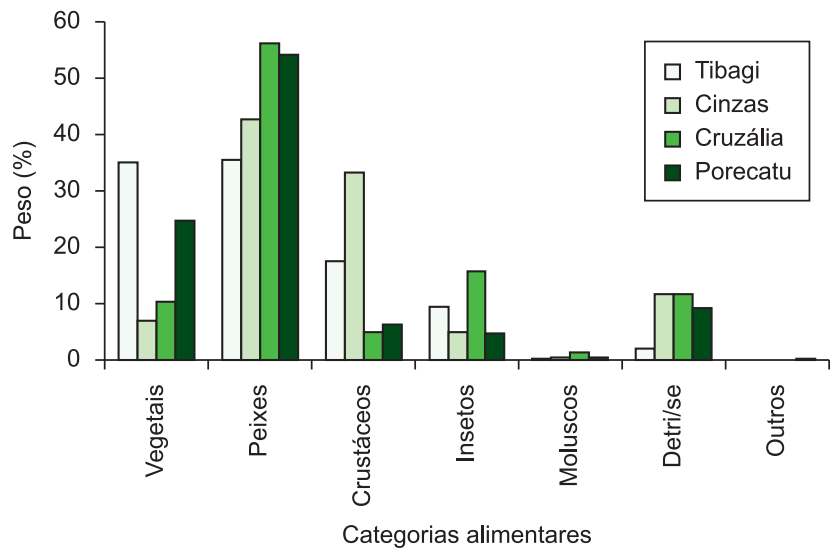

Figura 3. Percentuais em peso das categorias alimentares utilizadas pelos peixes, no total, nos quatro trechos do reservatório Capivara, no período maio/2001 a abril/2002.

Figure 3. Percentage by weight of food categories consumed by fish, in total, in the Capivara reservoir stretches, in the period May 2001 to April 2002. 
Bennemann, S.T. et al.

Tabela 1. Número de exemplares das espécies de peixes coletados nos quatro trechos do reservatório Capivara, no período de maio/2001 a abril/2002.

Table 1. Number of individuals of the fish species collected in four stretches from Capivara reservoir, period May/2001 to April/2002.

\begin{tabular}{|c|c|c|c|c|c|c|c|c|}
\hline \multirow{2}{*}{$\begin{array}{c}\text { Espécies } \\
\text { 1. Acestrorhynchus lacustris (Reinhardt, 1874) }\end{array}$} & \multicolumn{2}{|c|}{ Tibagi } & \multicolumn{2}{|c|}{ Cinzas } & \multicolumn{2}{|c|}{ Cruzália } & \multicolumn{2}{|c|}{ Porecatu } \\
\hline & 13 & 46 & 22 & 32 & 26 & 81 & 14 & 36 \\
\hline 2. Ageneiosus mititaris Valenciennes, 1836 & 0 & 1 & 4 & 7 & 0 & 0 & 0 & 0 \\
\hline 3. Apareiodon affinis (Steindachner, 1879) & 1 & 1 & 5 & 111 & 3 & 39 & 16 & 130 \\
\hline 4. Apareiodon piracicabae (Eigenmann, 1907) & 0 & 1 & 10 & 88 & 7 & 26 & 3 & 16 \\
\hline 5. Aphyocharax anisitsi Eigenmann \& Kennedy, 1903 & 0 & 2 & 6 & 79 & 1 & 4 & 0 & 0 \\
\hline 6. Astyanax altiparanae Garutti \& Britski, 2000 & 18 & 21 & 40 & 300 & 59 & 107 & 49 & 226 \\
\hline 7. Cichla kelberi Kullander \& Ferreira, 2006 & 4 & 4 & 0 & 21 & 3 & 25 & 69 & 181 \\
\hline 8. Crenicichla britskii Kullander, 1982 & 6 & 7 & 7 & 7 & 1 & 1 & 1 & 14 \\
\hline 9. Crenicichla niederleinii (Holmberg, 1891) & 0 & 2 & 2 & 23 & 7 & 7 & 0 & 13 \\
\hline 10. Cyphocharax modestus (Fernandez-Yepez, 1948) & 0 & 1 & 2 & 5 & 0 & 0 & 0 & 1 \\
\hline 11. Eigenmannia virescens (Valenciennes, 1847) & 5 & 9 & 7 & 15 & 0 & 0 & 2 & 3 \\
\hline 12. Galeocharax knerii (Steindachner, 1879) & 1 & 5 & 5 & 8 & 0 & 1 & 1 & 2 \\
\hline 13. Cichlasoma paranaense Kullander, 1983 & 10 & 10 & 0 & 0 & 0 & 0 & 0 & 0 \\
\hline 14. Gymnotus carapo Linnaeus, 1758 & 1 & 6 & 3 & 11 & 0 & 0 & 0 & 1 \\
\hline 15. Hoplias malabaricus (Bloch, 1794) & 10 & 29 & 4 & 17 & 0 & 9 & 1 & 3 \\
\hline 16. Hyphesobrycon eques (Steindachner, 1882) & 17 & 54 & 0 & 72 & 0 & 0 & 0 & 9 \\
\hline 17. Geophagus brasiliensis (Quoy \& Gaimard, 1824) & 0 & 0 & 0 & 2 & 0 & 0 & 9 & 22 \\
\hline 18. Hypostomus ancistroides (Ihering, 1911) & 1 & 23 & 14 & 52 & 0 & 0 & 0 & 0 \\
\hline 19. Hypostomus iheringii (Regan, 1908) & 0 & 0 & 1 & 1 & 0 & 0 & 0 & 0 \\
\hline 20. Hypostomus myersi (Gosline, 1947) & 0 & 0 & 1 & 1 & 0 & 0 & 0 & 0 \\
\hline 21. Iheringichthys labrosus (Kröyer, 1874) & 18 & 20 & 13 & 17 & 10 & 23 & 12 & 23 \\
\hline 22. Leporinus sp. & 3 & 8 & 0 & 5 & 0 & 0 & 0 & 0 \\
\hline 23. Leporellus vittatus (Valenciennes, 1850) & 0 & 1 & 1 & 1 & 0 & 0 & 5 & 6 \\
\hline 24. Leporinus elongatus Valenciennes, 1849 & 5 & 8 & 3 & 3 & 2 & 3 & 0 & 1 \\
\hline 25. Leporinus friderici (Bloch, 1794) & 5 & 11 & 4 & 5 & 1 & 1 & 1 & 4 \\
\hline 26. Leporinus obtusidens (Valenciennes, 1847) & 9 & 9 & 0 & 3 & 0 & 1 & 0 & 1 \\
\hline 27. Leporinus striatus Kner, 1859 & 0 & 3 & 1 & 9 & 0 & 0 & 0 & 0 \\
\hline 28. Loricaria prolixa Isbrücker \& Nijssen, 1978 & 0 & 0 & 2 & 2 & 0 & 0 & 0 & 0 \\
\hline 29. Loricariichthys platymetopon Isbrücker \& Nijssen,1979 & 37 & 148 & 51 & 95 & 101 & 228 & 10 & 18 \\
\hline 30. Metynnis maculatus (Kner, 1860) & 38 & 67 & 1 & 1 & 18 & 87 & 0 & 0 \\
\hline 31. Moenkhausia intermedia (Eigenmann, 1908) & 33 & 72 & 5 & 17 & 21 & 56 & 9 & 34 \\
\hline 32. Pimelodella avanhandavae (Valenciennes, 1840) & 0 & 0 & 6 & 6 & 0 & 0 & 0 & 0 \\
\hline 33. Pimelodus maculatus Lacépède, 1803 & 19 & 28 & 15 & 20 & 52 & 70 & 10 & 13 \\
\hline 34. Pininampus pirirampu (Spix, 1829) & 3 & 6 & 2 & 6 & 1 & 1 & 2 & 8 \\
\hline 35. Plagioscion squamosissimus (Heckel, 1840) & 96 & 169 & 39 & 53 & 41 & 104 & 32 & 70 \\
\hline 36. Pimelodus absconditus Azpelicueta, 1995 & 0 & 0 & 2 & 2 & 0 & 0 & 0 & 0 \\
\hline 37. Prochilodus lineatus (Valenciennes, 1836) & 0 & 2 & 2 & 12 & 0 & 0 & 0 & 0 \\
\hline 38. Rhynodoras d'orbigni (Kroöyer, 1855) & 2 & 3 & 12 & 13 & 0 & 0 & 0 & 0 \\
\hline 39. Porotergus ellisi Alonso de Arámburu, 1957 & 1 & 1 & 5 & 18 & 0 & 0 & 0 & 0 \\
\hline 40. Schizodon altoparanae Garavello \& Britski, 1990 & 0 & 1 & 1 & 4 & 0 & 0 & 0 & 0 \\
\hline 41. Schizodon intermedius Garavello \& Britski, 1990 & 9 & 21 & 1 & 25 & 0 & 72 & 0 & 0 \\
\hline 42. Schizodon nasutus Kner, 1859 & 4 & 12 & 5 & 30 & 9 & 10 & 28 & 45 \\
\hline 43. Serrapinnus notomelas (Eigenmann, 1915) & 4 & 9 & 5 & 24 & 1 & 6 & 0 & 0 \\
\hline 44. Serrasalmus maculatus Kner, 1858 & 31 & 33 & 7 & 41 & 15 & 17 & 2 & 10 \\
\hline 45. Sorubim lima (Bloch \& Schneider, 1801) & 0 & 0 & 0 & 2 & 0 & 0 & 0 & 0 \\
\hline 46. Sternopygus macrurus (Bloch \& Schneider, 1801) & 1 & 1 & 1 & 1 & 0 & 0 & 0 & 0 \\
\hline 47. Steindachnerina insculpta (Fernandez-Yepez, 1948) & 9 & 41 & 66 & 135 & 28 & 113 & 39 & 51 \\
\hline 48. Tilapia rendalli (Boulenger, 1896) & 0 & 0 & 0 & 4 & 0 & 0 & 1 & 7 \\
\hline 49. Triportheus angulatus (Spix \& Agassiz, 1829) & 41 & 57 & 0 & 2 & 10 & 12 & 0 & 0 \\
\hline Total exemplares coletados & - & 953 & - & 1408 & - & 1104 & - & 948 \\
\hline Total exemplares com conteúdo & 455 & - & 383 & - & 417 & - & 316 & - \\
\hline Total exemplares analisados & 574 & - & 475 & - & 541 & - & 479 & - \\
\hline
\end{tabular}


Tabela 2. Total de ocorrência (número) e peso (g) dos itens alimentares consumidos pelas espécies de peixes, nos trechos do reservatório Capivara, no período maio/2001 a abril/2002.

Table 2. Total occurrence (number) and weigh (g) of the food items consumed by fish species, from Capivara reservoir stretches, period May/2001 to April/2002.

\begin{tabular}{|c|c|c|c|c|c|c|c|c|}
\hline \multirow[t]{2}{*}{ Alimentos } & \multicolumn{2}{|c|}{ Tibagi } & \multicolumn{2}{|c|}{ Cinzas } & \multicolumn{2}{|c|}{ Cruzália } & \multicolumn{2}{|c|}{ Porecatu } \\
\hline & Ocor. & Peso & Ocor. & Peso & Ocor. & Peso & Ocor. & Peso \\
\hline 1. Restos vegetais & 98 & 65,4 & 100 & 7,24 & 103 & 18,46 & 84 & 19,51 \\
\hline 2. Sementes & 20 & 11,4 & 8 & 3,44 & 14 & 2,45 & 7 & 0,04 \\
\hline 3. Quirela & 33 & 18,4 & 4 & 1,18 & 1 & 0,06 & 12 & 10,12 \\
\hline 4. Sementes Polygonum sp. & 7 & 4,5 & 1 & 0,73 & 1 & 0,18 & 1 & 0,38 \\
\hline 5. Sementes Gramíneas & 4 & 0,3 & 2 & 2,18 & 7 & 1,36 & 25 & 18,37 \\
\hline 6. Trigo & 10 & 20,7 & 0 & 0 & 0 & 0 & 0 & 0 \\
\hline 7. Algas Filamentosas & 3 & 0,3 & 22 & 2,76 & 16 & 6,45 & 21 & 9,43 \\
\hline 8. P. squamosissimus & 8 & 19,7 & 2 & 14,89 & 3 & 25,22 & 2 & 11,14 \\
\hline 9. S. marmoratus & 2 & 1 & 1 & 11,93 & 1 & 0,42 & 0 & 0 \\
\hline 10. S. insculpta & 2 & 33,7 & 2 & 7,56 & 0 & 0 & 0 & 0 \\
\hline 11. A. altiparanae & 0 & 0 & 0 & 0 & 3 & 36,25 & 2 & 0,95 \\
\hline 12. M. intermedia & 0 & 0 & 0 & 0 & 1 & 1,09 & 0 & 0 \\
\hline 13. Restos peixes e N/I & 61 & 40,3 & 62 & 72,59 & 63 & 93,32 & 45 & 57,35 \\
\hline 14. Apareidon & 1 & 0,8 & 0 & 0 & 0 & 0 & 4 & 20,53 \\
\hline 15. Acestrorhynchus & 1 & 1 & 0 & 0 & 0 & 0 & 0 & 0 \\
\hline 16. Cichlidae & 1 & 6,2 & 0 & 0 & 0 & 0 & 0 & 0 \\
\hline 17. S. nasutus & 1 & 9,2 & 0 & 0 & 0 & 0 & 0 & 0 \\
\hline 18. S.spilopleura & 1 & 0,7 & 0 & 0 & 0 & 0 & 0 & 0 \\
\hline 19. Cichla & 3 & 10,3 & 0 & 0 & 1 & 1,74 & 8 & 36,63 \\
\hline 20. Camarão & 114 & 56,7 & 71 & 82,64 & 19 & 11,67 & 53 & 12,21 \\
\hline 21. Copepoda & 9 & 0 & 28 & 0,25 & 15 & 0,07 & 24 & 0,96 \\
\hline 22. Cladocera & 53 & 2,9 & 26 & 0,17 & 35 & 0,88 & 13 & 0,77 \\
\hline 23. Ostracoda & 59 & 1 & 12 & 0,12 & 74 & 1,21 & 19 & 0,18 \\
\hline 24. Restos crustáceos e N/I & 19 & 0,4 & 3 & 0,04 & 14 & 0,28 & 3 & 0,62 \\
\hline 25. Coleoptera & 14 & 1,4 & 9 & 0,35 & 15 & 3,88 & 5 & 0,1 \\
\hline 26. Odonata & 22 & 4,4 & 5 & 0,88 & 26 & 7,23 & 18 & 2,13 \\
\hline 27. Hemiptera & 7 & 0,9 & 1 & 0,01 & 5 & 0,37 & 1 & 0 \\
\hline 28. Ephemeroptera & 34 & 17 & 25 & 3,99 & 30 & 6,52 & 16 & 0,78 \\
\hline 29. Hymenoptera & 6 & 1,6 & 2 & 0,24 & 8 & 1,25 & 9 & 0,09 \\
\hline 30. Chironomidae & 33 & 2,3 & 47 & 1,12 & 73 & 9,24 & 40 & 4,64 \\
\hline 31. Outros Diptera & 17 & 0,9 & 7 & 0,35 & 29 & 0,73 & 16 & 0,62 \\
\hline 32. Ceratopogonidae & 5 & 0,1 & 10 & 0,07 & 19 & 0,15 & 16 & 0,68 \\
\hline 33. Caoboridae & 13 & 0,7 & 4 & 0,02 & 2 & 0,01 & 3 & 0,04 \\
\hline 34. Orthoptera & 2 & 1,2 & 0 & 0 & 0 & 0 & 0 & 0 \\
\hline 35. Trichoptera & 2 & 0,1 & 23 & 5,18 & 24 & 3,43 & 7 & 0,38 \\
\hline 36. Restos insetos e N/I & 33 & 2,3 & 73 & 3,92 & 82 & 11,34 & 48 & 1,64 \\
\hline 37. Gastropoda & 9 & 0,4 & 5 & 0,07 & 22 & 3,54 & 10 & 0,91 \\
\hline 38. Bivalvia & 12 & 0,3 & 14 & 0,87 & 0 & 0 & 4 & 0,04 \\
\hline 39. Detrito & 61 & 6,5 & 193 & 25,62 & 177 & 28,41 & 130 & 16,97 \\
\hline 40. Sedimento & 27 & 0,5 & 121 & 3,3 & 130 & 4,29 & 96 & 4,51 \\
\hline 41. Outros animais & 8 & 0,3 & 13 & 0,11 & 11 & 0,22 & 8 & 0,1 \\
\hline Total ocorrências & 815 & - & 896 & - & 1024 & - & 750 & - \\
\hline Total peso & - & 345,8 & - & 253,8 & - & 281,7 & - & 232,8 \\
\hline Número itens consumidos & 39 & - & 31 & - & 32 & - & 32 & - \\
\hline
\end{tabular}


A análise dos componentes principais, por composição percentual, distinguiu os alimentos que mais contribuíram para a construção dos eixos em cada trecho. O primeiro eixo explicou 90,2\% da variação total. Nos dois primeiros eixos os itens das categorias Peixes, Moluscos e Outros tiveram ocorrências semelhantes nos quatro trechos. No entanto, é possível verificar uma variação espacial no consumo de itens de outras categorias, o que gerou um padrão de discriminação para cada trecho. No trecho Tibagi a maior ocorrência foi dos itens da categoria Crustáceos, em Cinzas a tendência da categoria Insetos e, em Porecatu e Cruzália foi o alimento Detrito que discriminou estes dois trechos (Figura 4).

Através da dieta das principais espécies de peixes nos quatro trechos, com os valores dos itens alimentares (agrupados em amplas categorias) calculados pelo IAi, foram identificadas seis categorias tróficas. No trecho Tibagi, com as 14 espécies selecionadas, as seis categorias foram identificadas: carcinófaga, detritívora, herbívora, insetívora, onívora e piscívora. No trecho Cinzas 10 espécies foram incluídas em cinco categorias, não ocorrendo nenhuma espécie onívora. Nos trechos Cruzália e Porecatu, foram analisadas 11 e 12 espécies, respectivamente, foram identificadas apenas quatro categorias, não ocorrendo as carcinófaga e onívora (Tabela 3).

As proporções de indivíduos das espécies foram classificadas em categorias tróficas distintas em cada trecho. No trecho Tibagi foi alto o número de indivíduos que consumiram os itens camarão e detrito, mas apenas duas espécies foram classificadas como carcinófagas e detritívoras. No trecho Cinzas as espécies detritívoras dominaram em número de espécies e de indivíduos, e as insetívoras ocuparam o segundo lugar. No trecho Cruzália, as espécies detritívoras predominaram em número de indivíduos, seguidas pelas insetívoras. No trecho Porecatu predominaram em número de indivíduos as herbívoras e as piscívoras, seguidas das detritívoras e as insetívoras. (Figura 5).

Astyanax altiparanae, Moenkhausia intermedia e Pimelodus maculatus, consideradas generalista/oportunistas (sensu Gerking 1994) se destacaram por apresentar diferentes hábitos alimentares conforme o trecho analisado. Plagioscion squamosissimus, piscívora em Porecatu e Cruzália, comportou-se como carcinófaga nos trechos Tibagi e Cinzas.

Houve maior número de espécies insetívoras em Cruzália, de piscívoras em Tibagi e de detritívoras em Porecatu e Cinzas. A composição das principais espécies de peixe em abundância de exemplares foi distinta em cada trecho e, em cada um, houve predomínio de três espécies, com estrutura trófica também distinta. Em Cruzália, Loricariichthys platymetopon (detritívora), A. altiparanae (insetívora) e P. squamosissimus (piscívora); em Tibagi, P. squamosissimus (carcinófaga), L. platymetopon (detritívora) e $M$. intermedia (carcinófaga); em Porecatu, A. altiparanae (herbívora), Cichla monoculus (piscívora) e Apareiodon affinis (detritívora), em Cinzas, A. altiparanae (insetívora), S. insculpta (detritívora) e L. platymetopon (detritívora).

\section{Discussão}

O reservatório Capivara, caracterizado como de grande porte e entre os mais antigos do Brasil, neste estudo tem registrado pela primeira vez os recursos alimentares consumidos pelas principais espécies de peixes, em quatro trechos distintos. Foi constatado que em cada trecho os alimentos consumidos em ocorrência, ou em quantidade foram distintos. Entre os alimentos, os de origem alóctones utilizados pelos peixes do reservatório Capivara foram restos de cultivos (milho, soja e trigo) provenientes das terras adjacentes, o que diferiu dos reservatórios de menor porte e antigos investigados, onde os insetos terrestres tiveram importância como alimento para os peixes, como mostrado em uma síntese, em 24 reservatórios da bacia do Rio Paraná e áreas limítrofes, em estudo realizado por Fugi et al. (2005), em que foram registrados os recursos alimentares consumidos por 135 espécies de peixes. Estes autores verificaram maior quantidade de itens das categorias peixes e insetos terrestres consumidos pelos peixes, na maioria destes reservatórios.

Entre os reservatórios antigos do Brasil, o reservatório Capivari da bacia litorânea do Estado do Paraná, Abelha et al. (2005) constataram importante contribuição de itens alóctones na alimentação dos peixes, provenientes da vegetação no seu entorno. Dias et al. (2005) investigaram o reservatório de Lajes formado em 1908, na bacia do Rio Paraíba, e verificaram as principais espécies de peixes utilizando itens alimentares autóctones e alóctones, sendo os alimentos provenientes da coluna d'água (microcrustáceos) e do ecótono água/floresta nas áreas marginais constituídas de cobertura vegetal da Mata Atlântica.

Nos reservatórios recém construídos, Hahn et al. (1997) analisaram o reservatório de Segredo, após o primeiro ano de fomação, verificando os principais alimentos de 32 espécies de peixes. Neste reservatório, em ordem de importância, os recursos alimentares consumidos foram: insetos, vegetais, outros invertebrados, detritos/ sedimento, peixes, algas e microcrustáceos. Estes autores citam que

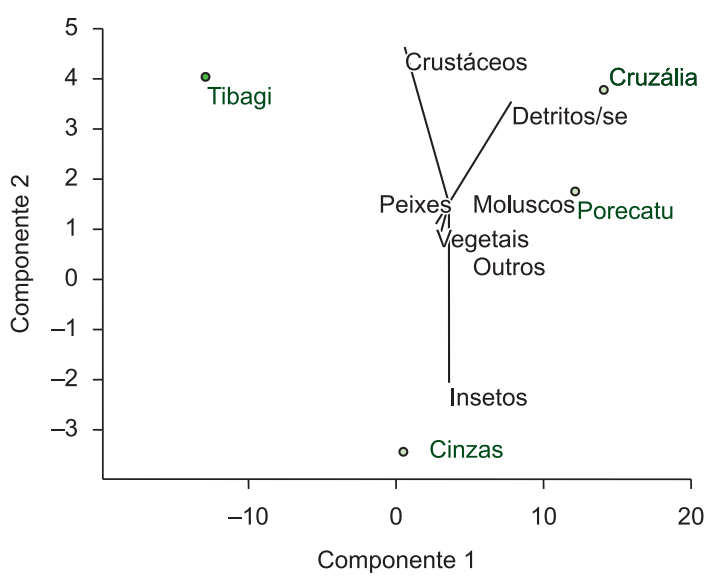

Figura 4. Projeções dos valores da composição percentual das categorias alimentares consumidas pelos peixes nos eixos 1 e 2, pela análise de componentes principais (ACP), nos quatro trechos do reservatório Capivara.

Figure 4. Projections of values of percentage composition of food categories, consumed by fish in the axes 1 and 2, by the principal components analysis (PCA), in the Capivara reservoir stretches.

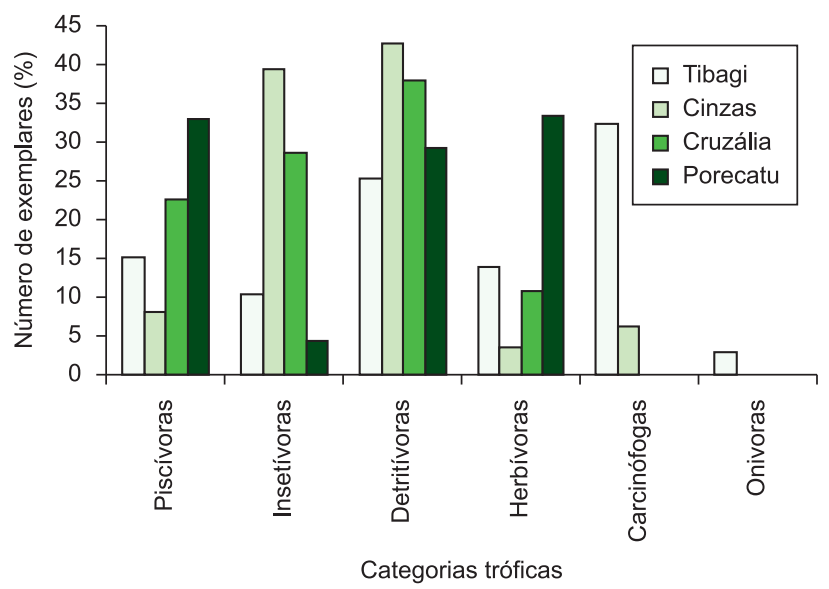

Figura 5. Estrutura trófica calculada pelo número de exemplares das espécies de peixes principais.

Figure 5. Trophic structure calculated by the number of the main species fish specimens. 
Tabela 3. Número de exemplares das principais espécies de peixes coletadas nos trechos do reservatório Capivara, no período maio/2001 a abril/2002. Classificação em categorias tróficas, baseada nos valores do Índice Alimentar (IAi).

Table 3. Number of individuals of principal fish species collected in the Capivara reservoir stretches, period May/2001 to April/2002. Classification in trophic categories based on the values of the Alimentary Index (IAi).

\begin{tabular}{|c|c|c|c|c|c|c|c|c|}
\hline \multirow[t]{3}{*}{ Espécies } & \multicolumn{8}{|c|}{ Trechos estudados } \\
\hline & \multicolumn{2}{|r|}{ Tibagi } & \multicolumn{2}{|c|}{ Cruzália } & \multicolumn{2}{|c|}{ Porecatu } & \multicolumn{2}{|c|}{ Cinzas } \\
\hline & $\mathbf{N}$ & Categoria & $\mathbf{N}$ & Categoria & $\mathbf{N}$ & Categoria & $\mathbf{N}$ & Categoria \\
\hline Apareiodon affinis & - & - & - & - & 130 & Detritíviora & - & - \\
\hline Apareiodon piracicabae & - & - & - & - & - & - & 88 & Detritívora \\
\hline Acestrorhynchus lacustris & 43 & Piscívora & 81 & Piscívora & 36 & Piscívora & 69 & Piscívora \\
\hline Astyanax altiparanae & 22 & Onívora & 107 & Insetívora & 242 & Herbíbora & 306 & Insetívora \\
\hline Cichla monoculus & - & - & - & - & 179 & Piscívora & - & - \\
\hline Geophagus brasiliensis & - & - & - & - & 22 & Detritívora & - & - \\
\hline Hoplias malabaricus & 29 & Piscívora & - & - & - & - & - & - \\
\hline Hypostomus ancistroides & - & - & - & - & - & - & 49 & Detritívora \\
\hline Iheringichthys labrosus & 20 & Insetívora & 23 & Insetívora & 24 & Insetívora & - & - \\
\hline Leporinus friderici & 11 & Herbívora & - & - & - & - & - & - \\
\hline Loricariichthys platymetopon & 148 & Detritívora & 228 & Detritívora & 18 & Detritívora & 95 & Detritívora \\
\hline Metynnis maculatus & 63 & Herbívora & 87 & Herbívora & - & - & - & - \\
\hline Moenkhausia intermedia & 72 & Carcinófaga & 57 & Insetívora & 34 & Detritívora & - & - \\
\hline Pimelodus maculatus & 28 & Herbívora & 70 & Insetívora & 13 & Insetívora & 20 & Insetívora \\
\hline Pinirampus pirinampu & 8 & Piscívora & - & - & - & - & - & - \\
\hline Plagioscion squamosissimus & 168 & Carcinófaga & 105 & Piscívora & 69 & Piscívora & 53 & Carcinófaga \\
\hline Rhinodoras d'orbigny & - & - & - & - & - & - & 13 & Insetivora \\
\hline Serrasalmus spilopleura & 33 & Piscívora & 17 & Piscívora & - & - & - & - \\
\hline Schizodon nasutus & - & - & 10 & Herbívora & 45 & Herbívora & 30 & Herbívora \\
\hline Steindachnerina insculpta & 40 & Detritívora & 113 & Detritívora & 48 & Detritívora & 136 & Detritívora \\
\hline Triportheus angulatus & 57 & Insetívora & - & - & - & - & - & - \\
\hline $\mathrm{N}^{\circ}$ de exemplares das espécies capturadas & 742 & - & 898 & - & 860 & - & 859 & - \\
\hline
\end{tabular}

as fontes alóctones são importantes na estruturação da comunidade de peixes nesta etapa, logo no início da formação do reservatório. Os resultados distintos nos trechos do reservatório Capivara, que em maior peso foram representados por itens da categoria peixes e, em ocorrência os itens das categorias detrito e insetos aquáticos foram os de maior importância em três dos trechos, crustáceos e insetos aquáticos em um dos trechos.

Dentre as 21 espécies de peixes principais estudadas entre os quatro trechos, as espécies detritívoras e piscívoras foram encontradas em maior número. Esses resultados são semelhantes aos que geralmente são encontrados em outros reservatórios mais antigos, como sumarizados por Araújo-Lima et al. (1995) e em estudos mais recentes realizados por Agostinho et al. (2007). No entanto, quando as espécies foram consideradas por número de indivíduos e por trecho, foi verificada uma composição trófica distinta e as espécies dominantes foram em número de apenas três, que totalizaram mais da metade do número de indivíduos capturados, tendo sempre uma das introduzidas entre as três espécies, em cada trecho.

Entre as espécies de peixes principais nos quatro trechos, três são alóctones às bacias dos Rios Paranapanema e Tibagi: C. monoculus, $P$. squamosissimus e T. angulatus. Segundo Gomes \& Miranda (2001), elas estão listadas entre as poucas espécies adaptadas aos ambientes lacustres. Esses autores constataram que, das três, apenas $P$. squamosissimus tornou-se abundante em todos os reservatórios em que foi introduzida. Neste estudo, essa espécie foi capturada em todos os trechos analisados. Cichla monoculus figurou entre as principais, apenas no trecho Porecatu e T. angulatus apenas em Tibagi.
As outras espécies figurantes entre as principais foram as nativas generatistas A. altiparanae, $M$. intermedia e $P$. maculatus. Também foram registradas nos principais reservatórios investigados por Dias \& Garavello 1998; Hahn et al. 1998; Andrian et al. 2001 e Cassemiro et al. 2002. Estas espécies se caracterizam por apresentar espectro alimentar amplo, compondo suas dietas com alimentos de origem vegetal e animal. Os alimentos utilizados podem revelar características dos reservatórios que estão habitando, pois são classificadas segundo o conceito (sensu Gerking 1994) como espécies oportunistas. Nos trechos estudados, estas espécies podem estar variando a dieta em função das condições resultantes de ações antrópicas e dos usos das áreas adjacentes, pois estão entre as espécies que melhor aproveitam a abundância de recursos sazonais e de origem alóctone (Lobón-Cerviá \& Bennemann 2000).

A estrutura trófica esteve relacionada com as características ambientais de cada trecho. No trecho Cruzália, formado por baías do reservatório de Capivara, caracteriza-se como ambiente lêntico e é o mais raso entre os trechos analisados. Neste trecho, está refletido o que relata Agostinho et al. (1999), que em reservatórios antigos e rasos, com menos de $10 \mathrm{~m}$ de profundidade, os alimentos encontrados em maior abundância são insetos e detritos. As espécies L. platymetopon (detritívora) e A. altiparanae (insetívora) foram as de maior abundância. Essas espécies, junto com $P$. squamosissimus, classificada como piscívora, representaram mais de $50 \%$ dos indivíduos ali coletados. Outras espécies como a piscívora Serrasalmus maculatus e a herbívora Metynnis maculatus também ocorreram em abundância, entre as principais, nesse trecho e em Tibagi, ambos caracterizados 
por apresentarem menor profundidade e macrófitas aquáticas em maior quantidade. $\mathrm{O}$ trecho Tibagi distingue-se por ser um ambiente de transição entre rio e reservatório, e neste trecho foi encontrado maior número de itens alimentares, bem como de categorias tróficas.

Já, no trecho Porecatu A. altiparanae, a mais abundante no local foi classificada como herbívora, pois consumiu quirela (milho quebrado usado como ceva) como alimento principal, diferente do trecho Cruzália onde foi considerada insetívora. No trecho Porecatu as áreas marginais são constantemente utilizadas por pescadores, que jogam este alimento no reservatório. Pimelodus maculatus, também foi classificada como herbívora em Tibagi, ingeriu, nesse trecho, além de quirela, sementes de milho e soja, culturas cultivadas alternadamente durante o ano, na totalidade de sua área marginal.

Plagioscion squamosissimus, considerada oportunista nos trechos Tibagi e Cinzas, teve sua dieta composta predominantemente por camarão, o que a incluiu na categoria carcinófaga, embora tenha mantido os itens da categoria peixes como um recurso importante de sua dieta. Nos outros trechos foi classificada como piscívora, pois os itens da categoria peixes foram seus principais alimentos. Investigando a dinâmica trófica dessa espécie nos Rios Tibagi e Paranapanema, Bennemann et al. (2006) constataram que o camarão Macrobrachium amazonicum (Heller, 1862), espécie introduzida, foi o principal item consumido por ela em determinados locais. Esta espécie de camarão utilizada por $P$. squamosissimus, também se estabeleceu e está bem-sucedida nos Rios Tibagi e Paranapanema. Enquanto que, as espécies nativas que servem de suas presas estão se alimentando de detritos, insetos aquáticos e de alguns itens alóctones sazonais introduzidos pelos pescadores, ou, levados para o reservatório, em consequiência dos cultivos de milho, trigo e outros, realizados em seu entorno.

A estrutura trófica do reservatório Capivara, que já possui mais de 30 anos e considerado antigo, foi composta por diferentes números de espécies de peixe e categorias tróficas em cada um dos trechos estudados. A maior ocorrência de determinados alimentos consumidos pelos peixes está relacionada com as três espécies de maior abundância em cada trecho: em Tibagi fizeram parte duas carcinófagas e uma detritivora; em Cinzas uma insetívora e duas detritívoras; em Cruzália uma detritívora, uma insetívora e a outra carcinófaga e em Porecatu, uma de cada categoria herbívora, piscívora e detritivora. Entre as três de maior abundância as espécies consideradas oportunistas representaram a maioria, mostrando a tendência que Hahn \& Fugi (2007) destacam, que as espécies generalistas tendem a predominar, ao longo do tempo, nestes ambientes.

Entre as espécies piscívoras, apenas no reservatório propriamente dito, no trecho Porecatu, houve participação desta categoria entre as três de maior abundância. Em estudos sobre a alimentação e estrutura trófica de peixes em reservatórios antigos realizados por Williams et al. (1998), por Dias et al. (2005), por Abelha et al. (2005), por Mol et al. (2007) e por Agostinho et al. (2007) foi verificada uma tendência em ter poucas espécies bem estabelecidas, onde as piscívoras e introduzidas se destacam.

\section{Agradecimentos}

A Oscar Akio Shibatta pela identificação das espécies de peixe, a Mário Luis Orsi (MZUEL) pela organização coordenação das coletas, aos técnicos: Edson Santana e Aparecido de Souza pelas coletas dos peixes. Ao convênio FUEL/UEL/DUKE ENERGY pelo suporte financeiro e ao IBAMA pela licença ( $\left.\mathrm{N}^{\circ} 083 / 2003\right)$.

\section{Referências Bibliográficas}

ABELHA, M.C.F., GOULART, E. \& PERETTI, D. 2005. Estrutura trófica e variação sazonal do espectro alimentar da assembléia de peixes do reservatório de Capivari, Paraná, Brasil. In Biocenoses em Reservatórios: padrões espaciais e temporais (L. Rodrigues, S.M. Thomaz, A.A. Agostinho \& L.C. Gomes, orgs.). RiMa Editora, São Carlos, p.197-209.
AGOSTINHO, A.A., MIRANDA, L.E., BINI, L.M., GOMES, L.C., THOMAZ, S.M. \& SUSUKI, H.I. 1999. Patterns of colonization in neotropical reservoirs, and prognosis on aging. In Theoretical reservoir ecology and its application (J.G. Tundisi \& M. Straskraba, eds.). International Institute of Ecology, Brazilian Academy of Sciences and Backhuys Publishers, São Carlos, p.227-265.

AGOSTINHO, A.A., GOMES, L.C. \& PELICICE, F.M. 2007. Os reservatórios brasileiros. In Ecologia e manejo de recursos pesqueiros em reservatórios do Brasil (A.A. Agostinho, L.C. Gomes, \& F.M. Pelicice, eds.). Eduem, Maringá, p.39-97.

ANDRIAN, I.F., SILVA, H.B.R. \& PERETTI, D. 2001. Dieta de Astyanax bimaculatus (Linnaeus, 1758) (Characiformes, Characidae), da área de influência do reservatório de Corumbá, estado de Goiás, Brasil. Acta Sci. 23(2):435-440.

ARAÚJO-LIMA, A.R.M., AGOSTINHO, A.A. \& FABRÉ, N.N. 1995. Trophic aspects of fish communities in brazilian rivers and reservoirs. In Limnology in Brazil (J.G. Tundisi, C.E.M. Bicudo, \& T. MatsumuraTundisi, eds.). ABC; SBL, Rio de Janeiro, p.105-136.

BENNEMANN, S.T. \& SHIBATTA, A.O. 2002. Dinâmica de uma assembléia de peixes do rio Tibagi. In A bacia do rio Tibagi (M.E. Medri, E. Bianchini, O.A. Shibatta \& J.A. Pimenta, orgs.). Eduel, Londrina, p.433-442.

BENNEMANN, S.T., SHIBATTA, O.A. \& GARAVELLO, J.C. 2000. Peixes da bacia do rio Tibagi: uma abordagem ecológica. Eduel, Londrina.

BENNEMANN, S.T., CAPRA, L.G., GALVES, W. \& SHIBATTA, A.O. 2006. Dinâmica trófica de Plagioscion squamosissimus (Perciforme, Sciaenidae) em trechos de influência da represa Capivara (Rios Paranapanema e Tibagi). Iheringia, Sér. Zool. 96(1):115-120.

CARVALHO, E.D. \& SILVA, V.F.B. 1999. Aspectos ecológicos da ictiofauna e da produção pesqueira do reservatório de Jurumirim. In Ecologia de reservatórios: estrutura, função e aspectos sociais (R. Henry, ed.). Fundibio, Botucatu, p.771-799.

CASATTI, L., MENDES, H.F. \& FERREIRA, K.M. 2003. Aquatic macrophytes as feeding site for small fishes in the Rosana reservoir, Paranapanema river, southeastern Brazil. Braz. J. Biol. 63(2):213-222.

CASSEMIRO, F.A.Z., HAHN, N.S. \& FUGI, R. 2002. Avaliação da dieta de Astyanax altiparanae Garutti \& Britski, 2000 (Ostheichthyes, Tetragonopterinae) antes e após a formação do reservatório de Salto Caxias, estado do Paraná, Brasil. Acta Sci. 24(2):419-425.

CASTRO, J.R., FORESTI, F. \& CARVALHO, E.D. 2003. Composição e abundância da ictiofauna na zona litorânea de um tributário, na zona de sua desembocadura no reservatório de Jurumirim, estado de São Paulo, Brasil. Acta Sci. 25(1):63-70.

DIAS, A.C.M.I., BRANCO, C.W.C. \& LOPES, G. 2005. Estudo da dieta natural de peixes no reservatório de Ribeirão das Lajes, Rio de Janeiro, Brasil. Acta Sci. 27(4):355-364.

DIAS, J.H. \& GARAVELLO, J.C. 1998. Ecological studies on the fish community of Salto Grande reservoir, Paranapanema river basin, São Paulo, Brasil. Verh. Int. Verein. Limnol. 26:2228-2231.

DUKE ENERGY INTERNATIONAL. 2003. Peixes do rio Paranapanema. Ed. Horizonte Geográfico, São Paulo.

FUGI, R., HAHN, N.S., LOUREIRO-CRIPPA, V.E. \& NOVAKOWSKI, G.C. 2005. Estrutura trófica da ictiofauna em reservatórios. In Biocenoses em reservatórios padrões espaciais e temporais (L. Rodrigues, S.M. Thomaz, A.A. Agostinho \& L.C. Gomes, orgs.). Rima, São Carlos, p.185-195.

GERKING, S.D. 1994. Feeding ecology of fish. Academic Press, San Diego.

GOMES, L.C. \& MIRANDA, L.E. 2001. Riverine characteristics dictate composition of the fish assemblages and limit fisheries in reservoirs of the upper Paraná river basin. Regul. Rivers: Res. Mgmt. 17:67-76.

HAHN, N.S., FUGI, R., ALMEIDA, V.L.L., RUSSO, M.R. \& LOUREIROCRIPPA, V.E. 1997. Dieta e atividade alimentar de peixes do reservatório de segredo. In Reservatório de Segredo: bases ecológicas para o manejo (A.A. Agostinho \& L.C. Gomes, eds.). Eduem, Maringá, p.41-162. 
HAHN, N.S., AGOSTINHO, A.A., GOMES, L.C. \& BINI, L.M. 1998 Estrutura trófica da ictiofauna do reservatório de Itaipú (Paraná-Brasil) nos primeiros anos de formação. Interciencia 23(5):299-305.

HAHN, N.S. \& FUGI, R. 2007. Alimentação de peixes em reservatórios brasileiros: alterações e conseqüências nos estágios iniciais do represamento. Oecol. Bras. 11(4):469-480.

HAMMER, O.; HARPER, D.A. \& RYAN, P.D. 2004. PAST - Paleontological Statistics ver.1.12 Disponível em http://www.folk.uio.no/ohammer/past (último acesso em 12/07/2006).

HOFFMANN, A.C., ORSI, M.L. \& SHIBATTA, O.A. 2005. Diversidade de peixes do reservatório da UHE Escola Engenharia Mackenzie (Capivara), rio Paranapanema. Bacia do alto rio Paraná, Brasil, e a importância dos grandes tributários na sua manutenção. Iheringia, Sér. Zool. 95(3):319-325.

HYSLOP, E.J. 1980. Stomach contents analysis: a review of methods and their application. J. Fish Biol. 17:411-429.

KAWAKAMI, E. \& VAZZOLER, G. 1980. Método gráfico e estimativa de índice alimentar aplicado no estudo de alimentação de peixes. Bol.Inst. Oceanogr. 29(2): 205-207.
KELMAN, J., PEREIRA, M.V.F., NETO, T.A.A. \& SALES, P.R.H. 2002. Hidreletricidade. In Águas doces no Brasil Capital ecológico, uso e conservação (A. Rebouças, B. Braga \& J.G.Tundisi, orgs.). Escrituras Editora, São Paulo, p.371-418.

LOBÓN-CERVIÁ, J. \& BENNEMANN, S.T. 2000. Temporal trophic shifts and feeding diversity in two sympatric, neotropical, omnivorous fishes: Astyanax bimaculatus and Pimelodus maculatus in rio Tibagi (Paraná, southern Brazil). Arch. für Hydrobiol. 149(2):285-306.

MOL, J.H., MÉRONA, B., OUBOTER, P.E. \& SAHDEW, S. 2007. The fish fauna of Brokopondo Reservoir, Suriname, during 40 years of impoundment. Neotrop. Ichthyol. 5(3):351-368.

TEIXEIRA, I. \& BENNEMANN, S.T. 2007. Ecomorfologia refletindo a dieta dos peixes em um reservatório no sul do Brasil. Biota Neotrop. 7(2):67-76.

WILLIAMS, J.D., WINEMILLER, K., TAPHORN, D.C. \& BALBAS, L. 1998. Ecology and status of piscivores in Guri, an oligotrophic tropical reservoir. North Amer. J. Fish. Manag. 18:274-285.

Recebido em 01/02/2010

Versão reformulada recebida em 08/10/2010

Publicado em 21/01/2011 